\title{
A COMPLICATION OF THE TEMPORARY PACEMAKER AND ANTIHYPERTENSIVE MEDICATIONS MAY CAUSE HEART BLOCK IN TERTIARY CARE HOSPITAL
}

\author{
L. SRILATHA ${ }^{*}$, N. DOONDI PHANI KUMAR ${ }^{2}$
}

Pharm D Student, Nirmala College of Pharmacy, Guntur, 522503, Andhra Pradesh

Email: lakhinanasrilath999@gmail.com

Received: 12 Sep 2021, Revised and Accepted: 16 Nov 2021

\begin{abstract}
Heart problem is a problem in the electrical signals in the heart. Electrical signals initiate a regular heartbeat that comes from the heart pacemaker, the sinoatrial node (SA), which is located at the top of the right atrium. Although the AV block is relative, the third-degree AV block is respectively rare. The incidence in the general population appears to be low, approximately $0.02 \%$ to $0.04 \%$. A 65 -year-old male patient admitted in the hospital with chief complaints of giddiness with sweating and history of symptomatic AV-block with no chest pain, shortness of breath. Patient underwent surgery of Inserted temporary pacemaker, permanent pacemaker and D-Data direction register (DDDr). In clinical use, the adverse effects of QTprolonging drugs can be checked by not exceeding the prescribed dose, withdrawing their use in patients with pre-existing cardiac disease, premature ventricular arrhythmias, and electrolyte imbalance such as hypokalemia. Simultaneous administration of drugs that inhibit the cytochrome P450. In emergency conditions, patients must keep in proper physicians and monitoring. This paper might help physician's research scholars, nursing staff, and other healthcare departments.
\end{abstract}

Keywords: Pacemaker, Antihypertensive medications, Heart block

(C) 2022 The Authors. Published by Innovare Academic Sciences Pvt Ltd. This is an open access article under the CC BY license (https://creativecommons.org/licenses/by/4.0/) DOI: https://dx.doi.org/10.22159/ijcpr.2022v14i1.44117 Journal homepage: https://innovareacademics.in/journals/index.php/ijcpr

\section{INTRODUCTION}

Heart problem is a problem in the electrical signals in the heart. Electrical signals initiate a regular heartbeat that comes from the heart pacemaker, the sinoatrial node (SA), which is located at the top of the right atrium [1]. The electrical signals transform to the lower chambers of the heart AV node (atrioventricular node). It maintains the heartbeat regularly. Heart block happens when the electrical signals are decreased due to the multi factors involved or depletion in electrical signals beneath the atrium [1, 2]. Heart block may depend on its own individuals or it may cause permanent damage to the heart and sometimes leads to requiring emergency treatment. There are three stages of heart block, which includes first-degree heart-block, second-degree (type-I and type-II), thirddegree heart block and bundle branch block [3, 4]. Beta-adrenergicblockers and non-dihydropyridine calcium channel blockers (CCB) are considered a common cause of acquired complete AV block (atrioventricular) in clinical cardiology practice [5, 6]. However, it is unclear if $\mathrm{AV}$ block is identified in patients treated with betaadrenergic-blockers and calcium channel blockers. On the other hands, if patients have drug-induced AV-block can expect a benign course after discontinuation of the offending medications [7]. Preceding evidence from extensive case series indicates that the majority of patients for whom drug discontinuation leads to the resolution of AV-block have a recurrence of heart block in the absence of therapy $[8,9]$. As a consequence of the high risk of AVblock recurrence despite the discontinuation of the suspected drug, about half of patients who have received Beta-blockers and CCB continuously develop AV-block ultimately require implantation of pacemaker [10].

\section{Epidemiology}

Although the AV block is relative, the third-degree $\mathrm{AV}$ block is respectively rare [11]. The incidence in the general population appears to be low, approximately $0.02 \%$ to $0.04 \%$ [12]. Similarly, as one looks at people with a more significant disease burden, the incidence increases with a study of patients in the veterans' health administration demonstrating an incidence at $1.1 \%$ in those with diabetes and $0.6 \%$ in those with hypertension [13]. Some works suggest that remodeling induced by atrial tachycardia impairs cellular calcium handling, reducing the calcium transient and thereby reducing cellular contractility [14]. The reduction in the calcium transient is likely to reduce the entry of calcium through down-regulated L-type channels, thus decreasing calcium receiving stores $[14,15]$.

\section{Case report}

A 65-year-old male patient was admitted in the hospital with chief complaints of giddiness with sweating and history of symptomatic AV-block with no chest pain, shortness of breath. Patient underwent surgery of Inserted temporary pacemaker, permanent pacemaker and D-Data direction register (DDDr) [Enticos 4D, safio S60, Safio S53 Biotronik] last year; they were performed lab investigations those are Cholesterol-221 mg/dl, HDL-32 mg/dl, Total HDL-6.9 $\mathrm{mg} / \mathrm{dl}, \mathrm{TG}-177 \mathrm{mg} / \mathrm{dl}, \mathrm{LDL}-153 \mathrm{mg} / \mathrm{dl}, \mathrm{VLDL}-35 \mathrm{mg} / \mathrm{dl}$, Non HDL$189 \mathrm{mg} / \mathrm{dl}$, Creatinine-2.70 mg/dl, Sodium-133 mmol/cu. mm, Potassium-5.1 mmol/l, GRBS-155 mg/dl, PR-60 beats/min, Respiratory Rate-16 breaths/min, blood pressure-140/80 $\mathrm{mmHg}$, later on the admission of the patient Pulse rate was decreased which is $37 \mathrm{bpm}$. Temporary pacemaker (TPI) MRI compatible device, done under aseptic conditions. TPI bilateral formed venous across was tried but under ultrasound found to have Iliac venous thrombosis due to pneumothorax across hence right jugular venous across is used for TPI insertion at RV apex pacing at 45 BPM. Permanent pacemaker insertion (PPI) is done via left axillary venous punctures, two short wires placed into SVC with RA. MRI compatible $\mathrm{RV}$ screwing lead is placed into RV apex septum and screwed parameters are good. Severely RA lead is used to place the lead at RAA and positioned. DDD was checked, and the device implanted into a pocket placed below the left subclavicular pocket. The final result was good, no complications. The final result was good and no complaints after insertion of pacemaker. Patient history of illness is Hypertension (for $10 \mathrm{y}$ ), Diabetes mellitus (for $10 \mathrm{y}$ ), Chronic kidney disease (for $2 \mathrm{mo}$ ), on regular medications, those are, T. gliclazide- 60 mg-once in a day (OD), T. Clopidogrel Rosuvastatin OD, T. chlorthalidone+cilnidipine Olmesartan-OD, T. metoprolol-25 mg-OD, T. Cilnidipine $10 \mathrm{mg}-\mathrm{OD}, \mathrm{T}$. pantoprazole-40 mg-OD.

\section{DISCUSSION}

Heart block is an abnormal heart rhythm that beats too slowly (bradycardia). In general, the heart receives the electrical signals for contraction and relaxation between the upper (atria) and the lower chamber (ventricles). In this case, as the patient receiving 
antihypertensive drugs like tablet. metoprolol-25 mg-once in a day and tablet. cilnidipine- 10 mg-once in a day. The mechanism of action of metoprolol is it binds to beta- 1 receptors and suppresses the cAMP, PKA and also inhibits the calcium channel receptors in corresponding to the patient receiving cilnidipine is a potential L-type calcium channel blocker that blocks the influx of the calcium. When calcium influx has reduced the contractions of the heart, and this leads to abnormal heart rhythms. Due to abnormal rhythms and complete heart block, the patient receives temporary pacemaker insertion. However, the insertion of the temporary pacemaker was done under aseptic conditions so, the permanent pacemaker insertion was done, and finally, the result was good and no other complaints.

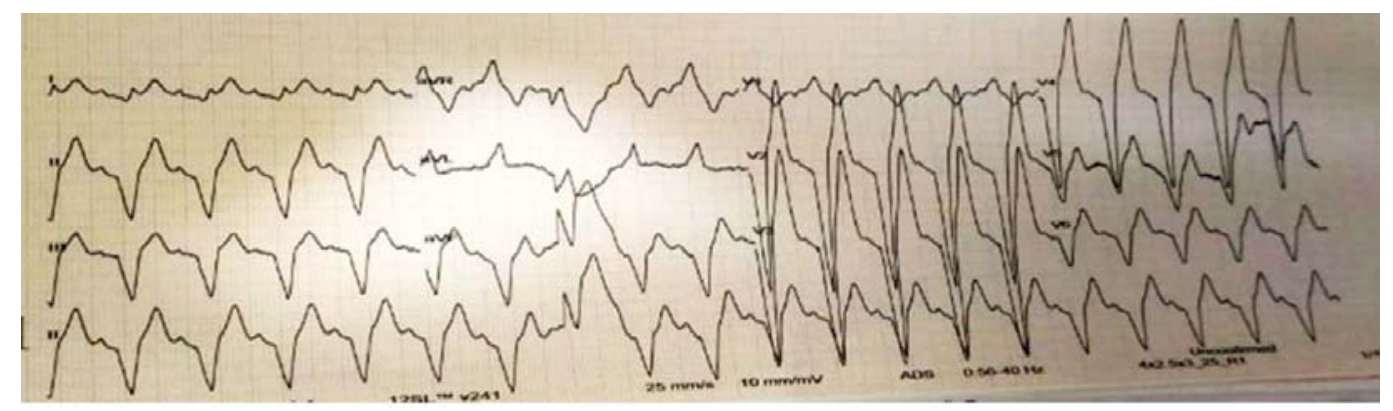

Fig. 1: Here we can observe the depletion of the PQRST waves in ECG during the heart block

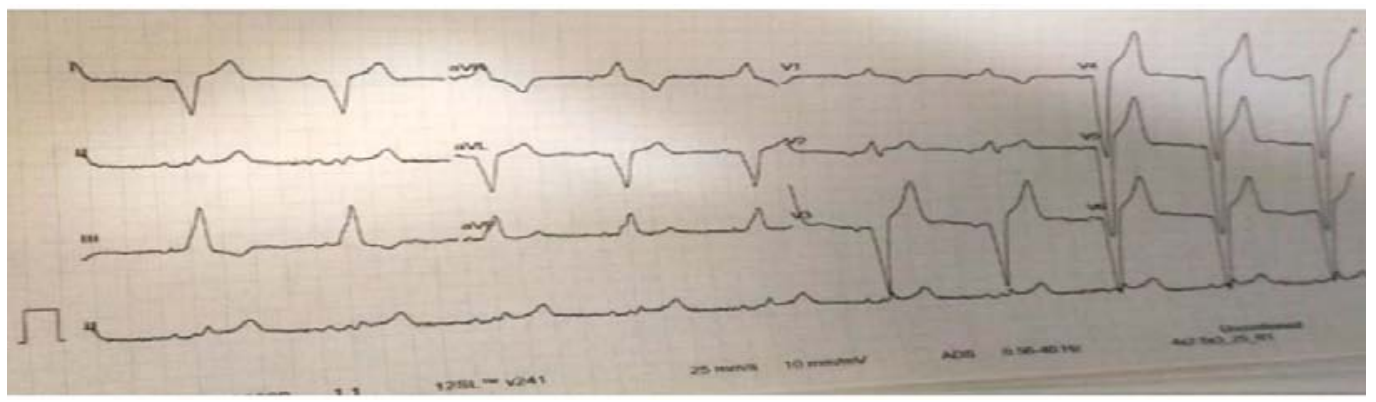

Fig. 2: Here ECG we can observe completely decrease the heart contractions

\section{Prevention of accidents in our life}

In clinical use, the adverse effects of QT-prolonging drugs can be checked by not exceeding the prescribed dose, withdrawing their use in patients with pre-existing cardiac disease, premature ventricular arrhythmias, and electrolyte imbalance such as hypokalemia. Simultaneous administration of drugs that inhibit the cytochrome P450 (for example, imidazole antifungals, macrolide antibiotics) or those that can increase the QT interval or drugs that produce electrolyte disturbance should be avoided. The serum potassium concentration should be monitored regularly as a matter of everyday care when the patient is on potassium-wasting diuretic.

Moreover, it may be regular clinical practice to perform ECGs routinely before and after the start or increase of dosage of a drug that may increase the QT interval. If the patient develops TdP, the offending drug should be discontinued, and electrolyte irregularities changed. Drugs that can prolong the QT period should ideally be prepared and continually updated in a national drug formulary, which is not the problem at present. Any adverse event indicative of cardiac arrhythmias should be informed urgently to drug safety authorities and drug manufacturers. The management of patients with drug-induced TdP includes identifying and withdrawing the offending $\operatorname{drug}(\mathrm{s})$, replenishing the potassium concentration to 4.5$5 \mathrm{mmol} / \mathrm{l}$, and infusing intravenous magnesium (1-2 g). In resistant cases, temporary cardiac pacing may be required to increase the heart rate and decrease the QT interval.

\section{CONCLUSION}

Drug-induced heart block is a rare condition; it means heart rhythm that means the heart beats too slowly than normal. Generally, some drugs like beta-blockers, calcium channel blockers, and antiarrhythmic cause heart block. As the patient using both betablockers and calcium channel blockers in the past affect the contractions and relaxation of the heart due to these medications,
However, the must remind it the antihypertensive category drugs may cause heart block with other comorbid condition, whenever administer the Antihypertensive drugs we must collect the history of any heart-related problems and other comorbidities concern the dosage adjustment based upon the body weight, Body mass index (BMI), Basal metabolic rate. In emergency conditions, patients must keep in proper physicians and monitoring. This paper might help physician's research scholars, nursing staff, and other healthcare departments.

\section{ABBREVIATION}

SA-senatorial node, AV node-atrioventricular node, DDDr-D-Data direction register, HDL-High-density lipoproteins, LDL-Low-density lipoprotein, VLDL-Very low-density lipoprotein, BMI-Body mass index

\section{FUNDING}

Nil

\section{AUTHORS CONTRIBUTIONS}

All the authors have contributed equally.

\section{CONFLICT OF INTERESTS}

\section{Declared none}

\section{REFERENCES}

1. Kusumoto F, Schoenfeld M, Barrett C, Edgerton J, Ellenbogen K, Gold M. ACC/AHA/HRS guideline on the evaluation and management of patients with bradycardia and cardiac conduction delay: executive summary: A report of the American College of Cardiology/American Heart Association Task Force on Clinical Practice guidelines, and the Heart Rhythm Society. Circulation. 2018;140(8):2019. 
2. Moslehi J, O'Gara PT. Book review: Braunwald's heart disease: A textbook of cardiovascular disease. J Intensive Care Med. 2007;22(2):123. doi: 10.1177/0885066606297694.

3. Heart block. Heart Block | UpBeat. Org-powered by the Heart Rhythm Society. Available from: https://upbeat.org/heartrhythm-disorders/heart-block. [Last accessed on 03 Nov 2021]

4. Tracy CM, Epstein AE, Darbar D, DiMarco JP, Dunbar SB, Estes NA, Ferguson TB, Hammill SC, Karasik PE, Link MS, Marine JE, Schoenfeld MH, Shanker AJ, Silka MJ, Stevenson LW, Stevenson WG, Varosy PD, Ellenbogen KA, Freedman RA, Gettes LS, Gillinov AM, Gregoratos G, Hayes DL, Page RL, Stevenson LW, Sweeney MO. American college of cardiology foundation, American heart association task force on practice guidelines, heart rhythm society. Circulation. 2012;126(14):1784-800. doi: 10.1161/CIR.0b013e3182618569, PMID 22965336.

5. Mangrum JM, DiMarco JP. The evaluation and management of bradycardia. N Engl J Med. 2000;342(10):703-9. doi: 10.1056/NEJM200003093421006, PMID 10706901.

6. Garg J, Messerli AW, Bakris GL. Evaluation and treatment of patients with systemic hypertension. Circulation. 2002; 105(21):2458-61. doi: 10.1161/01.cir.0000017143.59204.aa PMID 12034648

7. Gregoratos G, Abrams J, Epstein AE, Freedman RA, Hayes DL, Hlatky MA, Kerber RE, Naccarelli GV, Schoenfeld MH, Silka MJ, Winters SL, Gibbons RI, Antman EM, Alpert JS, Hiratzka LF, Faxon DP, Jacobs AK, Fuster V, Smith SC. American college of cardiology/American heart association task force on practice guidelines american college of cardiology/American heart association/North American society for pacing and electrophysiology committee. J Cardiovasc Electrophysiol. 2002;13(11):1183-99. doi: 10.1046/j.1540-8167.2002. 01183.x. PMID 12475117.
8. Zeltser D, Justo D, Halkin A, Rosso R, Ish-Shalom M, Hochenberg M, Viskin S. Drug-induced atrioventricular block: prognosis after discontinuation of the culprit drug. J Am Coll Cardiol. 2004;44(1):105-8. doi: 10.1016/j.jacc.2004.03.057, PMID 15234417.

9. Shohat-Zabarski R, Iakobishvili Z, Kusniec J, Mazur A, Strasberg B. Paroxysmal atrioventricular block: clinical experience with 20 patients. Int J Cardiol. 2004;97(3):399-405. doi: 10.1016/j.ijcard.2003.10.023, PMID 15561325.

10. Osmonov D, Erdinler I, Ozcan KS, Altay S, Turkkan C, Yildirim E, Hasdemir H, Alper AT, Cakmak N, Satilmis S, Gurkan K. Management of patients with drug-induced atrioventricular block. Pacing Clin Electrophysiol. 2012;35(7):804-10. doi: 10.1111/j.1540-8159.2012.03410.x, PMID 22530749.

11. Ostrander LD, Brandt RL, Kjelsberg MO, Epstein FH Electrocardiographic findings among the adult population of a total natural community, Tecumseh, Michigan. Circulation. 1965;31(6):888-98. doi: 10.1161/01.cir.31.6.888, PMID 14297523.

12. Johnson RL, Averill KH, Lamb LE. Electrocardiographic findings in 67,375 asymptomatic subjects. Am J Cardiol. 1960;6(1):15377. doi: 10.1016/0002-9149(60)90044-8. PMID 14407509

13. Benjamin E, Blaha M, Chiuve S, Cushman M, Das SR. Heart disease and stroke statistics-2017 update: a report from the American Heart Association. Circulation. 2017;135(10). doi: 10.1161/01.CIR.0000157741.99920.0C

14. Sun H, Gaspo R, Leblanc N, Nattel S. Cellular mechanisms of atrial contractile dysfunction caused by sustained atrial tachycardia Circulation. 1998;98(7):719-27. doi: 10.1161/01.cir.98.7.719, PMID 9715865.

15. Nattel S. Atrial electrophysiological remodeling caused by rapid atrial activation: underlying mechanisms and clinical relevance to atrial fibrillation. Cardiovasc Res. 1999;42(2):298-308. doi: 10.1016/s0008-6363(99)00022-x, PMID 10533568. 